\title{
Psychosocial Stressors among Suicide Attempters Attending JIPMER Hospital Puducherry
}

\author{
${ }^{1}$ Pinderfields General Hospital, NHS trust, UK \\ ${ }^{2}$ Faculty in Psychiatric Nursing, College of Nursing, JIPMER, India \\ ${ }^{3}$ Additional Professor, Department of Psychiatry JIPMER, India
}

Ansa Maria Mani ${ }^{1}$, Kavitha $\mathbf{R R}^{* 2}$ and Shivanad Katttimani ${ }^{3}$

Received: December 12, 2017; Published: December 21, 2017

*Corresponding author: : Kavitha RR, Tutor, College of Nursing, JIPMER, Puducherry, India

\section{Abstract}

Introduction: Suicide attempts are also viewed as unsuccessful lethal action and a possibility factor for future completed suicide.Psychosocial stressors in broader terms include interpersonal, social, familial, societal, psychological factors that can be the cause or consequences of stress. This study is aimed at identifying the psychosocial stressors of suicide attempters attending JIPMER hospital Puducherry.

Methods: A descriptive cross sectional survey was conducted at JIPMER hospital, Puducherry among 50 suicide attempters selected through convenience sampling. Semi structured questionnaire used for the study included demographic data sheet, Presumptive Stressful Life Event scale, Daily Hassles Scale-R, Beck's suicide intent scale. Data were analyzed using SPSS 20. Independent sample t-test, ANOVA and Pearson correlation were used as different statistical methods. AP value less than 05 was considered as statistically significant

Results: Family conflicts and financial problems were the stressful life events among the participants while alcohol use by self or family was the major daily hassle. Majority 26 (53\%) of the participants had moderate suicide intent. There was a significant association of psychosocial stressors with employment status with $\mathrm{p}=0.030$. Medical illness had relationship with daily hassles and suicide intent with $\mathrm{p}=.05$.

Conclusion: The most troubling psychosocial stressors were family based. This suggest family based intervention, focused on social intervention and tackling substance abuse in the family and teaching therapeutic interpersonal behaviors to reduce family conflicts may reduce the risk of future suicide attempts.

Keywords: Suicide; Suicide Intent; Daily hassles; Stress

\section{Introduction}

Living life to the fullest is the significant challenge faced by most of the people in this world. The value of the life is determined by how people give meaning to their life. Each person is a part of life [1]. All human beings will periodically experience psychological burdens, pain, and stressors during their lifetime. Having transient thoughts of wanting to die may be a natural response to emotional pain. In the midst of the psychological pain, suicide can become a gripping and viable means of escape [2]. Suicide then may be considered as both a coping mechanism and a failure to cope [3]. Suicide is the act of purposefully killing oneself. In broad terms, an act is a suicide if a person deliberately brings about his or her death in a situation where others do not coerce him or her to the action [4]. Suicide is not a diagnosis or a disease; it is a behavior that should alert us to an underlying problem, difficulty or disorder [5].

According to the WHO estimation each year approximately one million deaths from suicide globally, 16 people per 100,000 or one death in every 40 second. Suicide attempts are up to 20 times more habitual than completed suicides notably; a prior suicide attempt is the single most potent risk factor for death in the general population. Suicide is one among the three leading reason of death in the age group of 15-44 [6]. Although suicide rates have been highest amongst elderly males, rates among young people have been growing [7]. Mental health disorders (particularly substance abuse and depression) are associated with $90 \%$ of all cases of suicide. Death results from many complicated socio-cultural factors and is more likely to occur during periods of individual family and socioeconomic crisis [8]. the highest number of suicide deaths (16.927) was reported in Tamil Nadu in 2012, accounting for $12.5 \%$ of total suicide deaths in the country.

Pondicherry reported the highest rate of suicide (36.8) followed by Sikkim (29.1), Tamil Nadu (24.9), Kerala (24.3). The male: female ratio of suicide victims for the year 2012 was 66.2:33 [9]. Suicide is complex with biological, social, psychological, cultural and environmental factors. These stress factors vary from person 
to person and time to time. Identification of these stressors at the earliest will be the only solution to control the death statistics due to suicide. Suicide attempt is an urge for help from the environment; in more than $42 \%$ cases repeat attempts are known [10]. According to a London study by Royal College of Psychiatry, the primary triggers for self-harm were social and family, issues, relationship break-up [11]. According to the study conducted in Fiji among the clients with attempted suicide, the major stressor was the interpersonal loss $(69 \%)$ followed by family instability (36\%) [12]. Study done in Belgium observed that $42 \%$ of the victims had academic failures, and $36.8 \%$ of them had criminal offences [13].

Multicentre study by WHO in Europe concluded that $94.1 \%$ suicide attempters had a history of relationship conflicts, $79.2 \%$ reported a death or loss and $65.5 \%$ reported stress due to physical abuse [14]. Suicide is a preventable phenomenon. The many psychosocial stressors contributing to the suicide attempt can be avoided with timely intervention [15]. Understanding these stressors largely contribute to the future prevention strategies. Studies assessing stress full life events and suicidal intent are done nationally and internationally [16-19]. These studies mainly try to focus on one aspect of the stressors. The Present study is focusing on stressful events as well as day to day life stressors, and attempting to assess all the areas of psychosocial stressors in suicidal clients

\section{Methodology}

This cross sectional descriptive survey aimed to assess the psychosocial stressors among suicide attempters. The study was conducted in medical wards and crisis intervention clinic of Jawaharlal Institute of Post-graduate Medical Education and Research (JIPMER) hospital Puducherry. Main objective of the study was to assess the psychosocial stressors and suicide intent among the suicide attempters and to identify any association of these with demographic and clinical variable. Study population was patients admitted to the Medical Ward or attending Crisis Intervention Clinic in Psychiatric OPD after a suicide attempt, at JIPMER hospital Puducherry. Sample consisted of 50 suicide attempters. Subjects selected through convenience sampling technique that fulfilled the inclusion and exclusion criteria during the 6 weeks of study period. Patients with an attempted suicide aged above 18 years, both sex and Patients who can comprehend and speak English or Tamil were included.

Medically unstable patients were excluded from the study. Research instruments used were Presumptive Stressful Life Events Scale [20], Revised Daily Hassles Scale [21], and Beck's suicide intent Scale [22]. Data collected through direct interview technique. All the three instruments were validated in the Indian population and were standardized, at international, national settings. Reliability of Presumptive Stressful Life Event scale was assessed in Indian population and found to be satisfactory65 (0.8). Reliability studies of Beck's Suicide Intent Scale showed that internal consistency of the total score was acceptable67 (0.81). Daily hassle's scale was found to have good internal reliability66 (Cronbach's alpha 0.88). The JIPMER Scientific Committee as well as Institute ethics committee, Human studies JIPMER approval was obtained to conduct the study (PGMRC /MHN1/2014). The investigator approached the study subjects with a brief self-introduction. A written informed consent was procured from the subjects.

Psychosocial stressors were assessed by using Presumptive Stressful Life Events Scale and Revised Daily Hassles Scale. The scales were explained to the subjects in their convenient language and assistance was given to those who required. Suicide intent of the patient was assessed by Beck's Suicide Intent Scale; a clinicianrated scale and data collected by direct interview method. Privacy of the patients was taken care during the data collection, and the confidentiality was maintained throughout the research process. Statistical analysis was done using SPSS 20. Demographical and clinical variables were analysed with descriptive statistics. Patients mean stress scores and mean suicide intent score were computed using descriptive statistics. Chi square test and independent t test was used to find the association between socio demographicclinical variables and psychosocial stressors.

\section{Results}

Among the 50 participants females accounted for $56 \%(n=28)$ of the sample. Most of them were from nuclear family (58\%) and was married (58\%). Unemployed suicide attempters accounted for $58 \%$ of the sample and $74 \%$ of them hailed from rural area (Table 1). Alcohol use was reported by $28 \%$ of the subjects and only $10 \%$ of them had any history of Psychiatric illness. Chemical poisoning was the mode of attempt in majority of the attempters and only 10 $\%$ of them had a previous history of suicide attempt (Table 2). The most frequently occurred life event was family conflicts $31(62 \%)$. Second most commonly occurred event was financial loss or problem 25(50\%), followed by alcohol or drug use of the family member $20(40 \%)$ and marital conflict $19(38 \%)$. Change in sleeping pattern was the stressful event for 18 (36\%) subjects while 14 $(36 \%)$ of them had self or family unemployment as a stressful event. Conflict with in-laws was the stressful event for 8 (16\%) subjects and $6(12 \%)$ of the subjects identified to have the lack of child as a stressful event. (Figure 1) Use of alcohol 9(18\%) was the most frequently reported daily hassle. Troubling thoughts about the future, physical illness overload with family responsibilities $6(12 \%)$ equally occurred hassles. Among the study sample, at least $5(10 \%)$ had the hassles due to responsibilities, lack of money for food, television and menstrual problem (Figure 2).

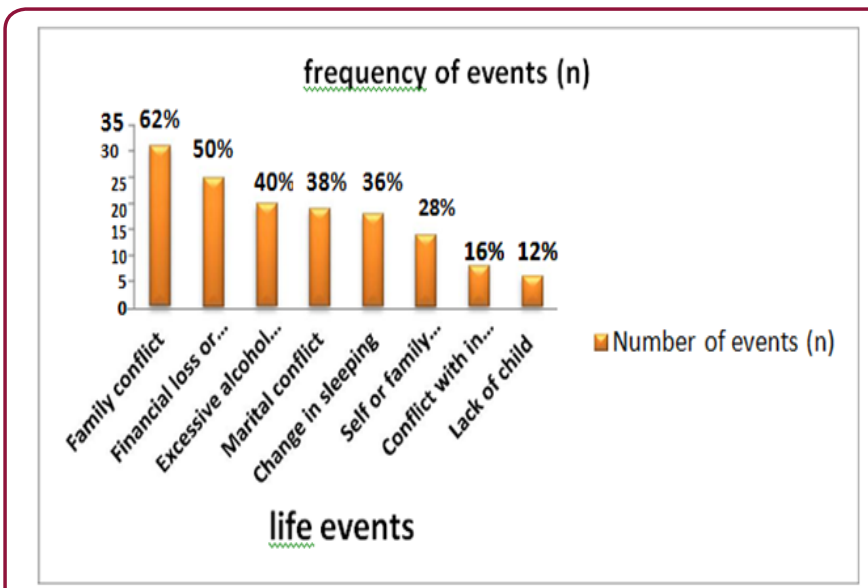

Figure 1: life events. 
Table 1: Socio-demographic data of sample.

\begin{tabular}{|c|c|c|c|c|}
\hline $\begin{array}{r}\text { Sl } \\
\text { no }\end{array}$ & \multicolumn{2}{|c|}{ Demographic variable } & $\begin{array}{c}\text { Number } \\
\text { (n) }\end{array}$ & $\begin{array}{c}\text { Percentage } \\
\text { (\%) }\end{array}$ \\
\hline \multirow{2}{*}{1} & \multirow{2}{*}{ Gender } & Male & 22 & 44 \\
\hline & & Female & 28 & 56 \\
\hline \multirow{3}{*}{2} & Marital & Married & 29 & 58 \\
\hline & \multirow{2}{*}{ Status } & Never married & 17 & 34 \\
\hline & & Separated/widowed & 4 & 8 \\
\hline \multirow{2}{*}{3} & \multirow{2}{*}{ Family type } & Nuclear & 29 & 58 \\
\hline & & Joint & 21 & 42 \\
\hline \multirow{2}{*}{4} & \multirow{2}{*}{ Education } & Literate & 42 & 84 \\
\hline & & Illiterate & 8 & 16 \\
\hline \multirow{2}{*}{5} & \multirow{2}{*}{$\begin{array}{l}\text { Working } \\
\text { status }\end{array}$} & Employed & 21 & 42 \\
\hline & & Unemployed & 29 & 58 \\
\hline \multirow{2}{*}{6} & \multirow{2}{*}{ Religion } & Hindu & 48 & 96 \\
\hline & & Non-Hindu & 2 & 4 \\
\hline \multirow{3}{*}{7} & \multirow{3}{*}{$\begin{array}{l}\text { Place of } \\
\text { residence }\end{array}$} & Urban & 3 & 6 \\
\hline & & Rural & 37 & 74 \\
\hline & & Semi Urban & 10 & 20 \\
\hline \multirow{2}{*}{8} & \multirow{2}{*}{ Nativity } & Native & 4 & 8 \\
\hline & & Non-Native & 46 & 92 \\
\hline
\end{tabular}

Table 2: Clinical variables of sample.

\begin{tabular}{|c|c|c|c|c|}
\hline SI no & \multicolumn{2}{|c|}{ clinical variable } & $\begin{array}{c}\text { Number } \\
\text { (n) }\end{array}$ & $\begin{array}{c}\text { Percentage } \\
\text { (\%) }\end{array}$ \\
\hline \multirow{2}{*}{1} & \multirow{2}{*}{$\begin{array}{l}\text { Current alcohol } \\
\text { use }\end{array}$} & Yes & 14 & 28 \\
\hline & & No & 36 & 72 \\
\hline \multirow{2}{*}{2} & \multirow{2}{*}{$\begin{array}{c}\text { No morbid } \\
\text { medical condition }\end{array}$} & Yes & 11 & 22 \\
\hline & & No & 39 & 78 \\
\hline \multirow{2}{*}{3} & \multirow{2}{*}{ Psychiatric illness } & Yes & 5 & 10 \\
\hline & & No & 45 & 90 \\
\hline \multirow{3}{*}{4} & \multirow{3}{*}{ Mode of attempt } & $\begin{array}{l}\text { Chemical } \\
\text { poisoning }\end{array}$ & 36 & 72 \\
\hline & & Natural plant & 10 & 20 \\
\hline & & Physical method & 4 & 8 \\
\hline \multirow{2}{*}{5} & \multirow{2}{*}{$\begin{array}{l}\text { Past suicide } \\
\text { history }\end{array}$} & Yes & 5 & 10 \\
\hline & & No & 45 & 90 \\
\hline Figu & 2: daily hassle & 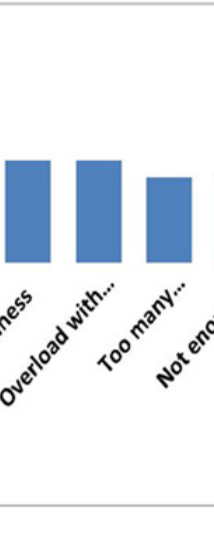 & & \\
\hline
\end{tabular}

In the regard of the suicide intent of the study subjects Majority $26(52 \%)$ of sample had medium suicide intent, while $23(52 \%)$ of them had low intent. suicide intent and only $1(2 \%)$ had high suicide intent. (Figure 3) \& (Table 3) Association of psychosocial stressors score with suicide intent severity $(\mathrm{N}=50)$ Spearman's correlation coefficient test showed that there was no significant correlation between the mean number of stressors obtained from Presumptive Stressful Life Event Scale and Daily Hassles Scale-R with suicide intent score. The association of demographic variables with suicide intent severity was established using Chi-square test results showed that there was no significant association between demographic variables and severity of suicide intent. Association of PSLE stresses scores with demographic variables. Independent $\mathrm{t}$ test results showed that employment status was associated with the life events score with $p=.030$. None of the other demographic variables were significantly associated with psychosocial stressors. Table 3 the association of PSLE scores with the clinical variables. Independent $\mathrm{t}$ test results elicited no significant association between psychosocial stressors and clinical variables except medical history with $\mathrm{p}=.053$. The association of DHS-R with clinical variables were assessed using Independent $t$ test showed no significant association between DHS-R stress score and clinical variables except medical history with $\mathrm{p}=.05$

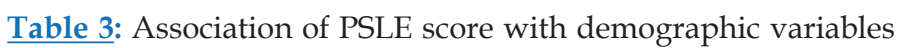
$\mathrm{N}=50$.

\begin{tabular}{|c|c|c|c|c|c|}
\hline Sl & \multicolumn{2}{|c|}{ Demographic variable } & No & PSLE mean & Statistical \\
\hline \multirow{2}{*}{1} & \multirow{2}{*}{ Gender } & Male & 22 & 185.18 & \multirow{2}{*}{$\begin{array}{l}t=2.427 \\
p=0.126\end{array}$} \\
\hline & & Female & 28 & 223.75 & \\
\hline \multirow{3}{*}{2} & \multirow{3}{*}{ Martial status } & Married & 29 & 224.34 & \multirow{3}{*}{$\begin{array}{l}f=2.721 \\
p=0.076\end{array}$} \\
\hline & & $\begin{array}{c}\text { Never } \\
\text { married }\end{array}$ & 17 & 168.24 & \\
\hline & & $\begin{array}{l}\text { Separated/ } \\
\text { Divorced }\end{array}$ & 4 & 243.25 & \\
\hline \multirow{3}{*}{3} & \multirow{3}{*}{ Type of family } & Nuclear & 29 & 211 & \multirow{3}{*}{$\begin{array}{c}f=0.08 \\
p=0.923\end{array}$} \\
\hline & & Joint & 20 & 201.35 & \\
\hline & & Extended & 1 & 193 & \\
\hline \multirow{2}{*}{4} & \multirow{2}{*}{$\begin{array}{l}\text { Education } \\
\text { level }\end{array}$} & Literate & 42 & 206.1 & \multirow{2}{*}{$\begin{array}{l}\mathrm{t}=3.079 \\
\mathrm{p}=0.086\end{array}$} \\
\hline & & Illiterate & 8 & 210.78 & \\
\hline \multirow{2}{*}{5} & \multirow{2}{*}{ Employment } & Employed & 29 & 184.34 & \multirow{2}{*}{$\begin{array}{c}\mathrm{t}=4.977 \\
\mathrm{p}=0.030^{*}\end{array}$} \\
\hline & & Unemployed & 21 & 237.76 & \\
\hline \multirow{2}{*}{6} & \multirow{2}{*}{ Religion } & Hindu & 48 & 206.29 & \multirow{2}{*}{$\begin{array}{l}\mathrm{t}=0.048 \\
\mathrm{p}=0.828\end{array}$} \\
\hline & & Non Hindu & 2 & 218.5 & \\
\hline \multirow{3}{*}{7} & \multirow{3}{*}{$\begin{array}{l}\text { Place of } \\
\text { residence }\end{array}$} & Urban & 3 & 196 & \multirow{3}{*}{$\begin{array}{l}\mathrm{t}=0.083 \\
\mathrm{p}=0.92\end{array}$} \\
\hline & & Rural & 37 & 209.84 & \\
\hline & & Semi Urban & 10 & 198.7 & \\
\hline \multirow[b]{2}{*}{8} & \multirow[b]{2}{*}{ Native } & Pondicherry & 4 & 165 & \multirow{2}{*}{$\begin{array}{l}\mathrm{t}=0.976 \\
\mathrm{p}=0.328\end{array}$} \\
\hline & & $\begin{array}{c}\text { Non } \\
\text { Pondicherry }\end{array}$ & 46 & 210.78 & \\
\hline
\end{tabular}

*significant 


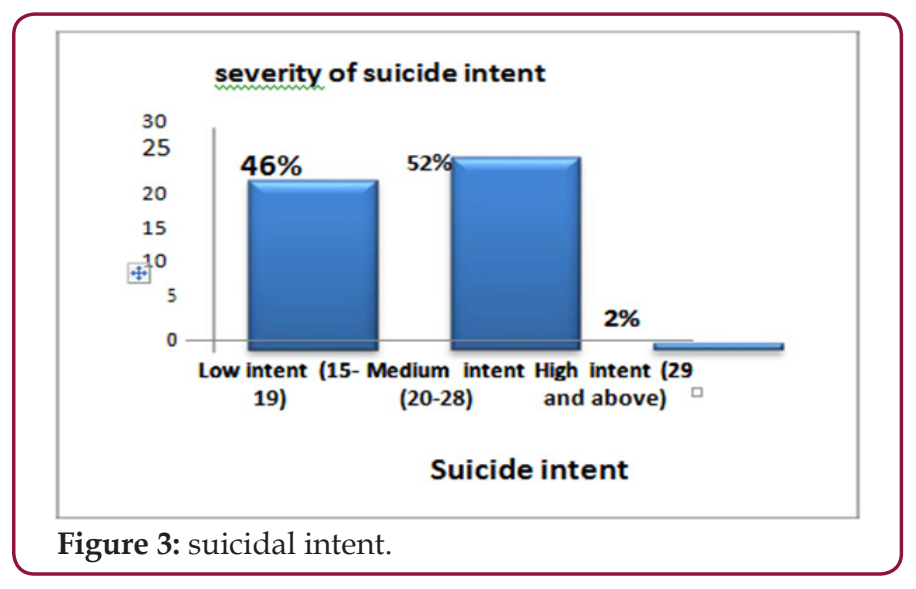

\section{Discussion}

Supporting to the current study findings various national and international studies also reports increased suicide attempts among the females. Chinese study [23] reported that the females are at higher risk of attempting suicide. Similar demographic descriptions were found from an Indian study [24] done by Mathew in Southern India. Majority of the suicide attempters were females $62(62 \%)$, and 84 (84\%) were from the nuclear family. Among the attempters 70 (70\%) of them were Hindus. Concerning employment $80(80 \%)$ of them had high school education and 55 (55\%) were unemployed. History of suicide attempt was found in $8(8 \%)$, and $4(4 \%)$ of them had physical illness. Another Indian study [25] resulted that the male-female ratio of suicide attempters was almost equal to one (1:1.4). Higher proportion 80 (54.3\%) of the suicide attempters were married which coincided with the findings of the current study, stating that marriage is a possible risk for suicide attempts. The majority 146 (98.6\%) of the attempters were of Hindu religion as seen in our study. There were some findings contradicting to the current study results. In the current study majority 29 (58\%) of them belonged to nuclear family, and most were 42 (84\%) literate and. Very low number of subjects 5 (10\%) had past history of suicide attempt, and psychiatric illness. Study from Orissa [26] reported that majority 129 (87\%) of the suicide attempters had an extended family, and most of them were educated.

South Indian [27] study reported that 13 (13.3\%) suicide attempters had a family history of suicide attempts and majority 78 $(78 \%)$ of the suicide attempters had history of psychiatric illness. However, there are also reports which suggest that psychiatric illness is very low in suicide attempters from Asia [18]. Family conflicts accounted for the major stressful life event of $62 \%$ of the study subjects while $50 \%$ of the subjects had financial loss or problems. Excessive alcohol or drug use by a family member was a reason for stress for $40 \%$ of the subjects. Marital conflicts and change in sleeping pattern accounted for stress in 38\% and $36 \%$ of the study subjects respectively. Mean stressors score of 50 study subject for the presumptive stressful life event scale was 206.8 with a standard deviation of 88.2.

The results of a Belgium study [28] on life events of suicide attempters showed that $8(42.1 \%)$ of them had relational problems, but the majority of them had academic failures since majority of the study subjects were adolescence. Another international study [29] also supported the present study results that $44(72.1 \%)$ of the study subjects had family-related conflicts and 39 (63.9\%) of them had marital conflicts. The reviewed studies have given various results. An international study done in UK reported a high suicide intent score in $63 \%$ of males $79 \%$ of females. Another study [30] done among 229 suicide attempters in Finland resulted that $40 \%$ of them had severe suicide intent followed by another $40 \%$ of them with moderate suicide intent. Mild suicide intent was present in $20 \%$ of the attempters. Indian studies done on suicide intent had tried to classify the high and low intent attempters; study done by Kumar et al.

The present study assessed the association of suicide intent with the psychosocial stressors of suicide attempters. No significant association was elicited between psychosocial stressors and suicide attempt in the study. Neither the stress arising from major life events nor stress arising from daily hassles showed association with the suicide intent. A study done in the same setting [31] of the present study failed to observe an association of suicide intent with any of the demographic or clinical variable except a significant $(\mathrm{p}=0.04)$ association with psychiatric illness. There was a significant association found with the PSLE score and employment status. Being unemployed may indirectly increases stress by adding financial burden and family conflict. Other studies have not commented on this. There were no studies with a similar result. Study done by Pompli [32] reported that psychosocial stressors are significantly higher in repeaters than that of first time attempters. Another study from Iran found a significant difference $(p<0.001)$ in the stress score of male and female suicide attempters. Study Limitations were samples were limited to 50 due to the inclusion and exclusion criteria, The study period was limited to 6 weeks, Sampling technique adopted in the study was convenience sampling, There were some sensitive issues like emotional distress anxiety familial conflicts; however asking about them by using questionnaires always carries concerns about the truthfulness of the participants.

\section{Acknowledgement}

The authors thank all the clients who participated in the study as well as JIPMER hospital for giving permission and support to conduct the study.

\section{References}

1. (2001) World Health Organization. Prevention of suicide. Public health Geneva, Paper No. 35.

2. Bertolote JM (1993) Guidelines for the primary prevention of mental, Neurological, psychological disorders. IV Suicide, Geneva: World Health Organization.

3. Hagnell O, Rorsman B (1980) Suicide in the Lundby study: A controlled prospective investigation of stressful life events. Neuro psychobiology 6(6): 319-332.

4. Chang EC, Sanna LJ, Hirsch JK, Jeglic EL (2010) Loneliness and negative life events as predictors of hopelessness and suicidal behaviors in Hispanics: Evidence for a diathesis-stress model. Journal of Clinical Psychology 66(12): 1242-1253.

5. Hawton K, Saunders KE, O'Connor RC (2012) Self-harm and suicide in adolescents. Lancet 379: 2373-2382. 
6. Holmes TH, Rahe RH (1967) the social readjustment rating scale. Journal of Psychosomatic Research 11(12): 213-218.

7. Vijayakumar L, Nagaraj K, Pirkis J, Whiteford H (2005) Suicide in developing countries: frequency, distribution, and association with socioeconomic indicators. Crisis 26(3): 104-111.

8. Choi H, Marks NF (2011) Socioeconomic status, marital status continuity and change, marital conflict, and mortality. Journal of Aging Health 23(4): 714-742.

9. (2010) National institute of Mental health 2010. The numbers count: mental disorders in America.

10. (2003) World Health Organization. Suicide Prevention (SUPRE) 2003.

11. (2014) World health organization. Preventing suicide is a global imperative 2014.

12. Vijaykumar L (2007) Suicide and its prevention: The urgent need in India. Indian Journal of Psychiatry 49(2): 81-84.

13. Radhakrishnan R (2012) Suicide: An Indian perspective. Indian J Psychiatry. 2012; Oct- Dec; 54(4): 304-319.

14. (2015) Self-harm suicide and risk: helping people who self-harm. Final report of a working group. Royal College of Psychiatrists, London.

15. Connie Henson, Alan Taylor, Joanne Cohen, Alita Q Waqabaca, Saral Chand (2012) Attempted suicide in Fiji. Suicidology Online 3: 83-91.

16. Portzky G, Audenaert K, Heeringen K (2009) Psychosocial and psychiatric factors associated with adolescent suicide: a case-control psychological autopsy study. The Journal of Adolescence. 2009; Aug 32(4): 849-862.

17. Osvath P, Voros V, Fekete S (2004) Life events and psychopathology in a group of suicide attempters. Psycho-pathology 37(1): 36-40.

18. Singh G (1984) Presumptive Stressful Life Events scale (PSLE) A new stressful life events scale for use in India. Indian Journal of Psychiatry 26(2): 107-114.

19. Kar N (2010) Profile of risk factors associated with suicide attempts: A study from Orissa, India. The Indian Journal of Psychiatry 52(1): 48-56.

20. Kumar PN (1998) Age and gender related analysis of psychosocial factors in attempted suicide. Indian J Psychiatry 40(4): 338-345.

21. Jeffrey EH, Kennetii A (1992) The Daily Hassles Scale (Revised): Does it Measure Stress or Symptoms. Behavioral Assessment 14(3-4): 465-482.
22. Beck AT, Kovacs M, Weissman A (1979) Assessment of suicidal intention: The scale for suicidal ideation. Journal of Consulting and Clinical Psychology 47(2): 343-352.

23. Zhang Ji, Xu H (2007) Degree of suicide intent and the lethality of means employed: a study of Chinese attempters. Research Suicide Attempters 11(4): 343-350.

24. Nazarzadeh M, Bidel Z, Ayubi E, Asadollahi K, Carson KV, et al. (2013) Determination of the social related factors of suicide in Iran: a systematic review and meta-analysis. BMC Public Health 4(13): 14-15.

25. Mathew A, Nanoo S (2013) psychosocial stressors and patterns of coping in adolescent suicide attempters. Indian Journal of Psychiatry Medicine 35(1): 39-46.

26. Pour FB, Seyed Mehdi Tabatabaei, Nour-Mohammad Bakhshani (2014) Epidemiology of Suicide and its Associated Socio-demographic Factors in Patients Admitted to Emergency Department of Zahedan Khatam-AlAnbia Hospital. International journal of high risk behavior and addiction 3(4): e22637.

27. Portzky G, Audenaert K, Heeringen K (2009) Psychosocial and psychiatric factors associated with adolescent suicide: a case-control psychological autopsy study. The Journal of Adolescence 32(4): 849-862.

28. Kar N (2010) Profile of risk factors associated with suicide attempts: A study from Orissa, India. The Indian Journal of Psychiatry 52(1): 48-56.

29. Conner KR, Houston RJ, Swogger MT, Conwell Y, You S, et al. (2012) Stressful life events and suicidal behavior in adults with alcohol use disorders: role of event severity, timing, and type. Drug and Alcohol Dependence 120(1-3): 155-161.

30. Mathew A, Nanoo S (2013) Psychosocial stressors and patterns of coping in adolescent suicide attempters. Indian J Psychology Medicine 35(1): 39-46.

31. Menon V, Kattimani S, Shrivastava MK, Thazath HK (2013) Clinical and socio- demographic correlates of suicidal intent among young adults: a study from South India. Crisis 34(4): 282-288.

32. Pompili M, Innamorati M, Szanto K, Di Vittorio C, Conwell Y, et al. (2011) Life events as precipitants of suicide attempts among first-time suicide attempters, repeaters, and non-attempters. Psychiatry Research 186(23): $300-305$.

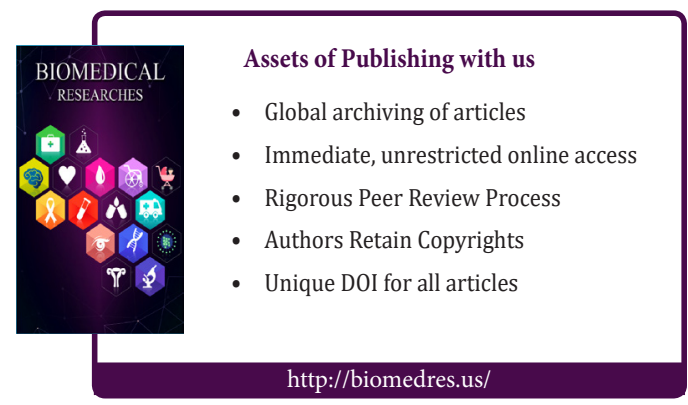

